International Journal of Engineering Technology and Scientific Innovation

ISSN: 2456-1851

Volume: 05, Issue: 01 "January-February 2020"

\title{
EFFECTS OF ROTATION ON EFFICIENCY OF A GAS TURBINE ROTOR
}

\author{
Agatha Mbeni Muinde, Eng. Dr. Hiram Ndiritu, Dr. Benson Gathitu
}

Jomo Kenyatta University of Agriculture and Technology

DOI: 10.46609/IJETSI.2020.v05i01.001 URL: https://doi.org/10.46609/IJETSI.2020.v05i01.001

\begin{abstract}
Economic growth, industrialization and global population are increasing every day leading to high-energy demand. There is a demand for low cost, reliable, efficient power plants with reduced emissions. Coal is a leading source of energy accounting for $41.5 \%$ of the world electricity and $26.5 \%$ of global primary needs. 400 million tonnes of coal ranging from lignite to sub-bituminous and calorific value between 16 and $27 \mathrm{MJ} / \mathrm{kg}$ were discovered in Mui Basin Kitui county Kenya. Coal plants are now of interest in Kenya hence there is a need of efficient and clean energy. This paper is on simulation results of optimization of gas turbine system for power generation using syngas from Mui Basin coal. The rotation speed of gas turbine rotor was varied and the results compared against expected performance reported to show the effects on gas turbine efficiency.
\end{abstract}

Keywords: Efficiency, Gas turbine, tip leakage, TIT

\section{INTRODUCTION}

The rise in global population and economic growth has led to energy crisis [ 1]. A $25 \%$ increase is expected between 2014 and $2040.85 \%$ of the energy consumed globally in the $20^{\text {th }}$ century was fossil fuels [2]. The electricity consumption in Kenya can be used to show energy demand. By 2030 the electricity demand is expected to be 15,000 MW an increase from 1,191 MW as at 2013 [3]. The government has started projects that will spur the demand which are; iron ore smelting, standard gauge and light rail, ICT parks that are being constructed, the LAPSET project, rural electrification programs, school computer programs [4]. The 5000+ MW 40 months' generation program has been started to meet the expected rise in demand. The program is expected to lower the cost electricity from US\$ cents 19.78 to 10.43 for domestic and from US\$ cents 14.14 to 9.00 for industrial and commercial [5]. 
Fossil fuels are a major source of global energy and at the end of the $20^{\text {th }}$ century they accounted for $85 \%$ of the total energy consumed [2]. Coal accounts for one third of the energy used in electric power generation and it is the main source of energy in U.S., India, China, Russia and Kazakhstan [6]. Coal has the highest $\mathrm{CO} 2$ emission per thermal energy compared to other fossil fuels [7]. Low efficiency and high level of pollution of coal-fired power plants has led to alternative uses of coal.

A gas turbine is used to convert the thermal energy into mechanical energy. Gas turbines are light, compact and have a high power to weight ratio [8]. Figure1 shows a schematic diagram of the actual gas turbine engine. It consist of compressor, combustor and turbine. The compressor is used to compress air from the atmosphere to the desired pressure, the combustor is used to burn fuel and the compressed air raising the gas temperature and the turbine converts the gas energy into power work and is coupled to the load, which can be a generator for power generation or used to drive other systems.

Gas turbines are used to power ships, jets, airplanes and also for power generation. Gas turbines can operate on both liquid and gaseous fuels. The solid fuels such as coal, petroleum coke, biomass, municipal waste and other carbonaceous materials can also be gasified and cleaned then used in a gas turbine as synthetic gas (syngas). Gas turbines are preferred for power generation because of their low level of $\mathrm{CO} 2$ and NOx emissions, small installation time and space and high cycle efficiency [9].

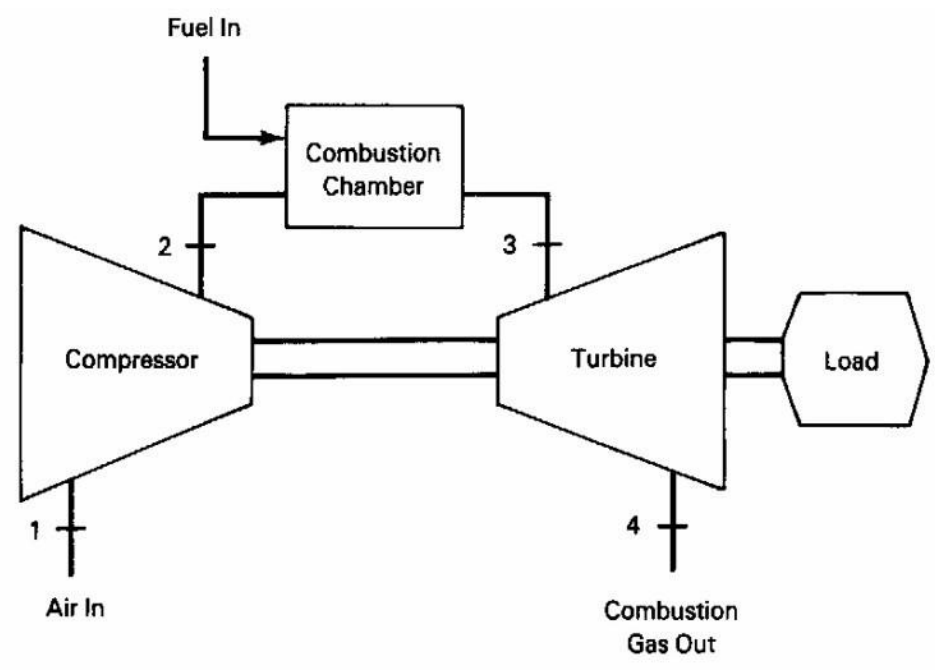

Figure 1: Schematic diagram of a gas turbine engine

\section{Blade Tip Clearance}


Blade tip clearance is the space between the blade and the casing and is responsible for leakage mass flow across the blade tip from the pressure side to the suction side as shown in Figure 2. Third of all the aerodynamic losses experienced in a stage are caused by tip leakage loss [10] . The leakage causes reduced turbine efficiency by decreasing networkoutput of each rotor, hence reducing the turbine leakage loss can instantly reduce the operation cost, increase efficiency and increase the engine life [11].

The gas turbine rotation causes blade tip losses due to the vortices formed as the fluid passes between the blades and the casing. Liu et al [12] on the effects of blade rotation on axial turbine tip leakage vortex breakdown and loss. The finding were that the tip mixing loss per unit leakage flow reduced with increase in rotation speed. Coriolis force and the 3D shear flow in the casing end-wall region influenced the vortex breakdown. Tip injection should be used to control vortex breakdown hence reducing tip leakage losses.

Yang [13] did a numerical simulation to study tip leakage flow and heat transfer in rotor blade with flat and squealer tips. Leakage flow was reduced by increasing the tip groove depth up to $3 \%$ of the blade span above which any increase tip gap height caused increase in leakage flow. When the tip gap height was less than $1 \%$ the overall heat transfer coefficient was affected by both vortex structure and leakage velocity but when the tip gap was more than $1 \%$ increase in heat transfer coefficient was proportional to increase in tip gap height which can only result from a variety of the leakage velocity.

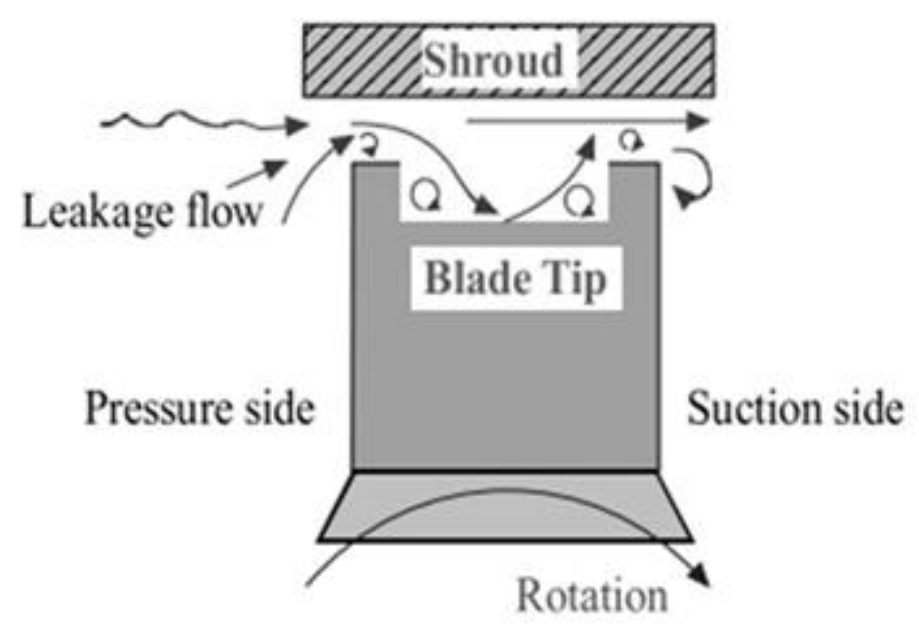

Figure 2: Tip Leakage

\section{Gaps}

1. More research is needed to establish the best rotation speed for least leakage flow. 
2. Research is needed to establish the optimum flow rate of syngas.

3. Research is ongoing to establish an optimum blade area for syngas turbine.

\section{METHODOLOGY}

\section{Solver Description}

The modeling software used in this paper was the CFD code ANSYS Workbench and CFX 17.2 academic version [14] Finite volume approach was used to discretize the steady threedimensional Navier-Stoke equation for compressible ideal gas [15]. The standard $\mathrm{k}-\varepsilon$ model was used in this paper to model the turbulence flow; all the model constants were used in their default form. While scalable turbulence wall function was used.

Three-dimensional computational domain, which included one blade of the gas turbine rotor, was used in the simulation. The blade mesh was a structured multi- block grid system generated using ANSYS TurboGrid software. The mesh had 146,234 nodes, 136,455 elements and maximum edge length ratio of 349.682 as shown in Figure3. ANSYS CFX was used for analysis, steady state conditions were used. The rotational speed was varied from 3000 RPM to $15000 \mathrm{RPM}$, at a temperature of $900 \mathrm{~K}$ and at a pressure ratio of $10 \mathrm{rp}$. The outlet mass flow rate was set at $0.06 \mathrm{kgs}^{-1}$, while the solver parameters were set at high resolution and convergence control of physical timescale of $0.002 \mathrm{~s}$.

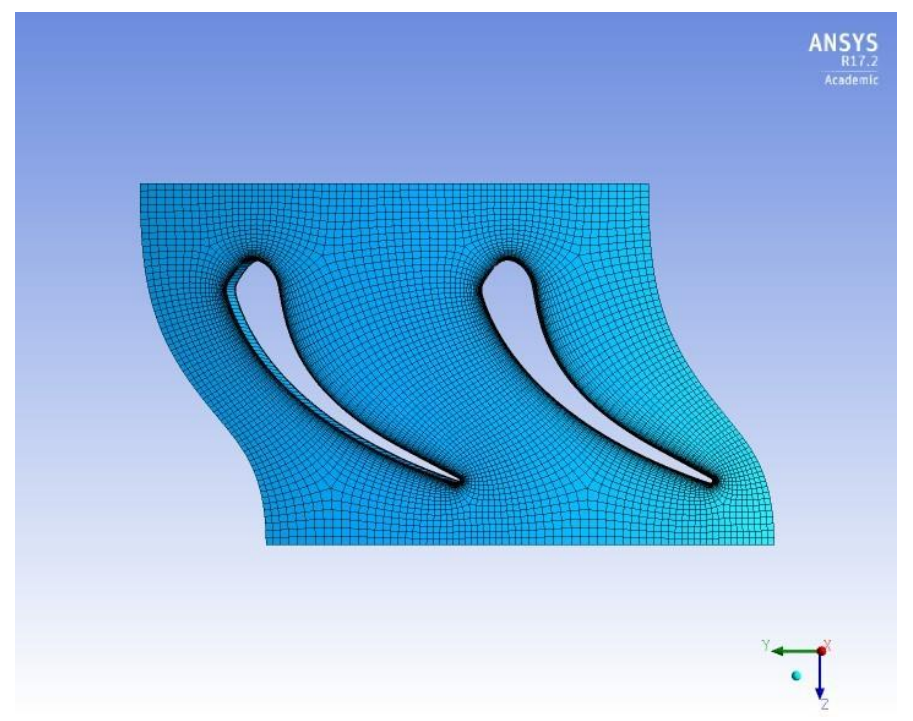

Figure 3: Rotor mesh

\section{Conservation Equations}


To test the performance some of the governing equations are:

1. Mass conservation equation

$$
\left(\nabla \cdot V_{\mathrm{i}}\right)=0
$$

2. Momentum conservation equation

$$
\rho\left(\nabla . V_{i}\right)=F_{i}-\nabla . P+\mu \nabla^{2} V_{i}
$$

3. Energy conservation equation

$$
\boldsymbol{\nabla}\left[\left(\boldsymbol{\nabla} \cdot \rho \mathrm{V}_{\mathbf{i}}\right)\left(\mathrm{C}_{\mathbf{p}} \mathrm{T}\right)-\frac{\lambda}{\mathrm{C}_{\mathrm{p}}} \boldsymbol{\nabla} \cdot\left(\mathrm{C}_{\mathbf{p}} \mathrm{T}_{\mathbf{i}}\right)\right]=-\mathbf{H}
$$

4. $\mathrm{k}$ - equation

$$
\begin{aligned}
\rho \frac{\partial k}{\partial t}+\rho\left\langle u_{i}\right\rangle & \frac{\partial k}{\partial x_{j}} \\
& =2 \mu_{t}\left\langle s_{i j}\right\rangle \frac{\partial\left\langle u_{i}\right\rangle}{\partial x_{j}}-\rho \epsilon+\frac{\partial}{\partial x_{j}}\left[\left(\mu+\frac{\mu_{t}}{\sigma_{k}}\right) \frac{\partial k}{\partial x_{j}}\right]
\end{aligned}
$$

5. $\epsilon$ - equation

$$
\begin{aligned}
\rho \frac{\partial \epsilon}{\partial t}+\rho\left\langle u_{i}\right\rangle & \frac{\partial \epsilon}{\partial x_{j}} \\
& =C_{e 1} P_{k} \frac{\epsilon}{k}-C_{e 2} \rho \frac{\epsilon^{2}}{k}+\frac{\partial}{\partial x_{j}}\left[\left(\mu+\frac{\mu_{t}}{\sigma_{\epsilon}}\right) \frac{\partial \epsilon}{\partial x_{j}}\right]
\end{aligned}
$$

\section{RESULTS}

Gas turbine rotor performance characteristics; torque, power and total-to-total polytropic efficiency were obtained for varied rotational speed and at constant pressure and turbine inlet temperature, while the inlet conditions were kept as mentioned above. The data obtained was recorded and used to plot graphs of Torque, power and total polytropic efficiency as shown in 
Figures 4,5 \& 6. The relationship of power, torque and angular speed is shown by Equation 6, where $\mathrm{P}$ is power, $\mathrm{T}$ is torque and $\omega$ is the angular speed.

$$
P=T \omega
$$

The curves plotted in Figure 4 and 5 were consistent with Equation 6. Torque was inversely proportional to angular speed. The torque was maximum at the lowest angular speed. Power was proportional to angular speed up to a maximum point of $5805.96 \mathrm{~W}$ at 12000RPM then started decreasing. The polytropic efficiency increased with increase in rotational speed up to a maximum of $70.46 \%$ at 9000RPM, then started to decrease as shown in Figure 6.

\section{DISCUSSION}

Entropy of a turbine rotor increases streams wise with the maximum being at the trailing edge. Vortex mixing at the rotor trailing edge is responsible for the high entropy, which results in efficiency drop. The maximum polytropic efficiency was achieved at 9000RPM any increase in rotational speed after that lead to a drop. Figure 7 to 10 shows change in entropy at 8000rpm, 9000rpm 13000rpm and 15000rpm. The contours at the tip show region of high entropy, which was caused by tip clearance leakages and it was responsible for the drop in efficiency and also the power drop.

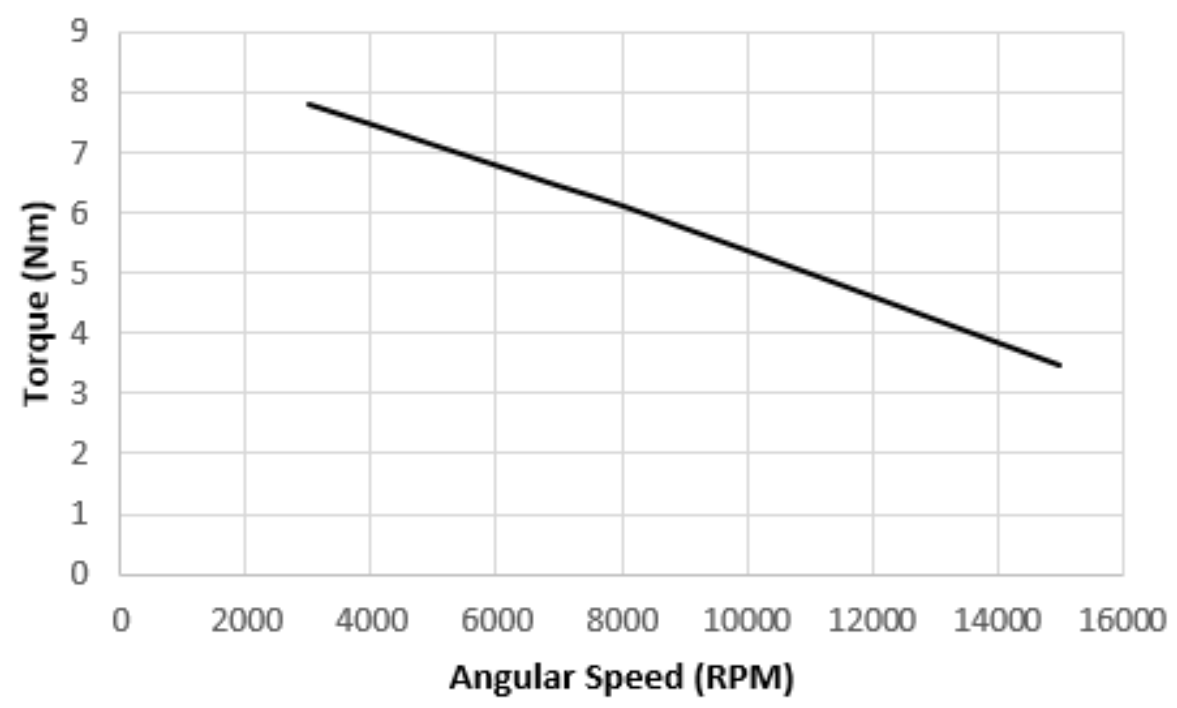

Figure 4: Graph of Torque against Rotational Speed 
International Journal of Engineering Technology and Scientific Innovation

ISSN: 2456-1851

Volume: 05, Issue: 01 "January-February 2020"

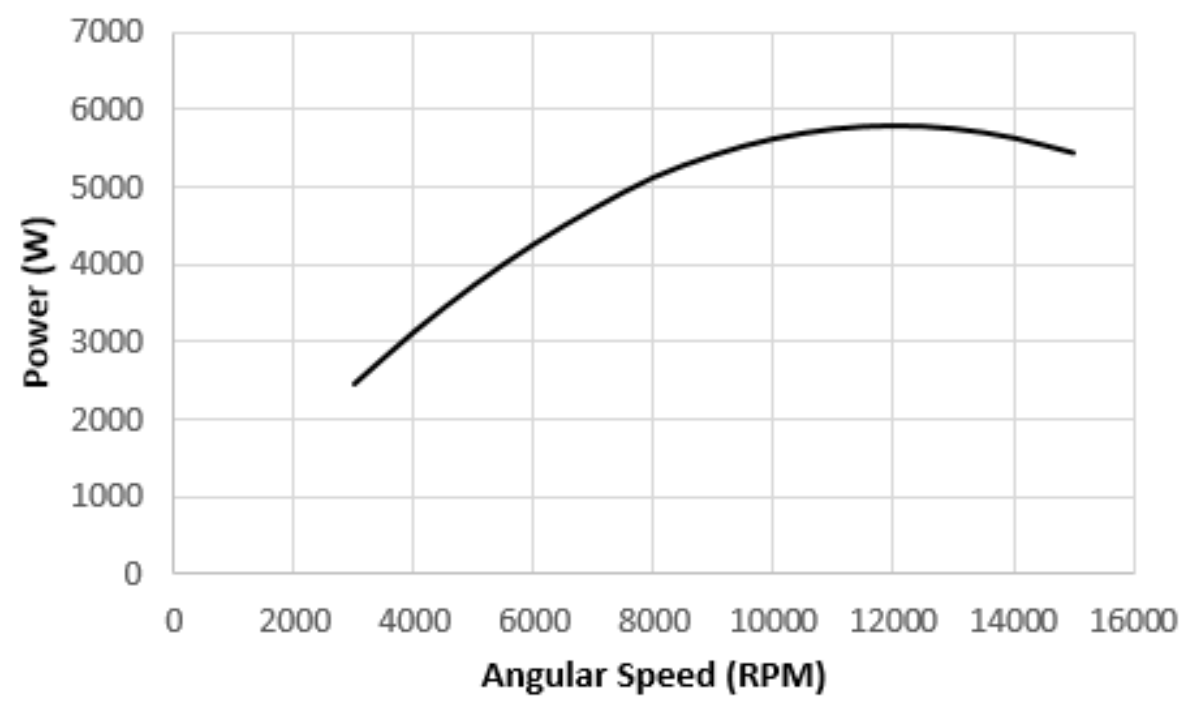

Figure 5: Graph of Power against Rotational Speed

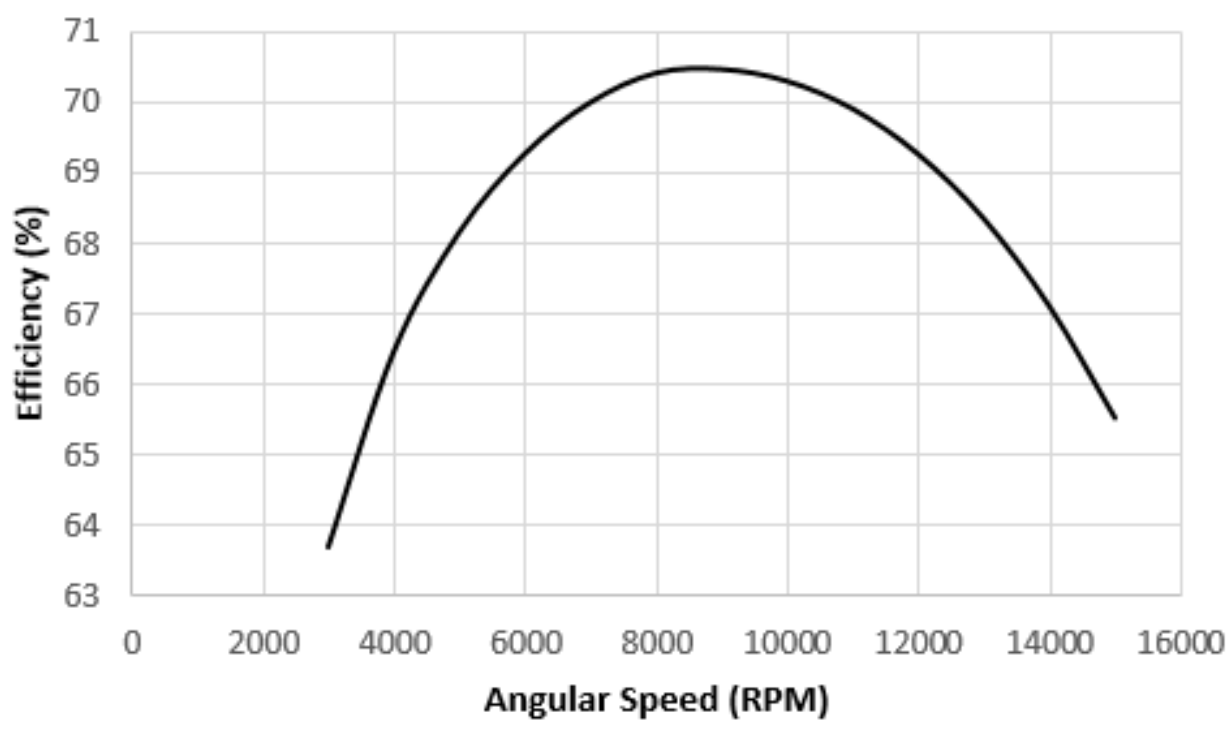

Figure 6: Graph of Polytropic Efficiency against Rotational Speed 
International Journal of Engineering Technology and Scientific Innovation

ISSN: 2456-1851

Volume: 05, Issue: 01 "January-February 2020"

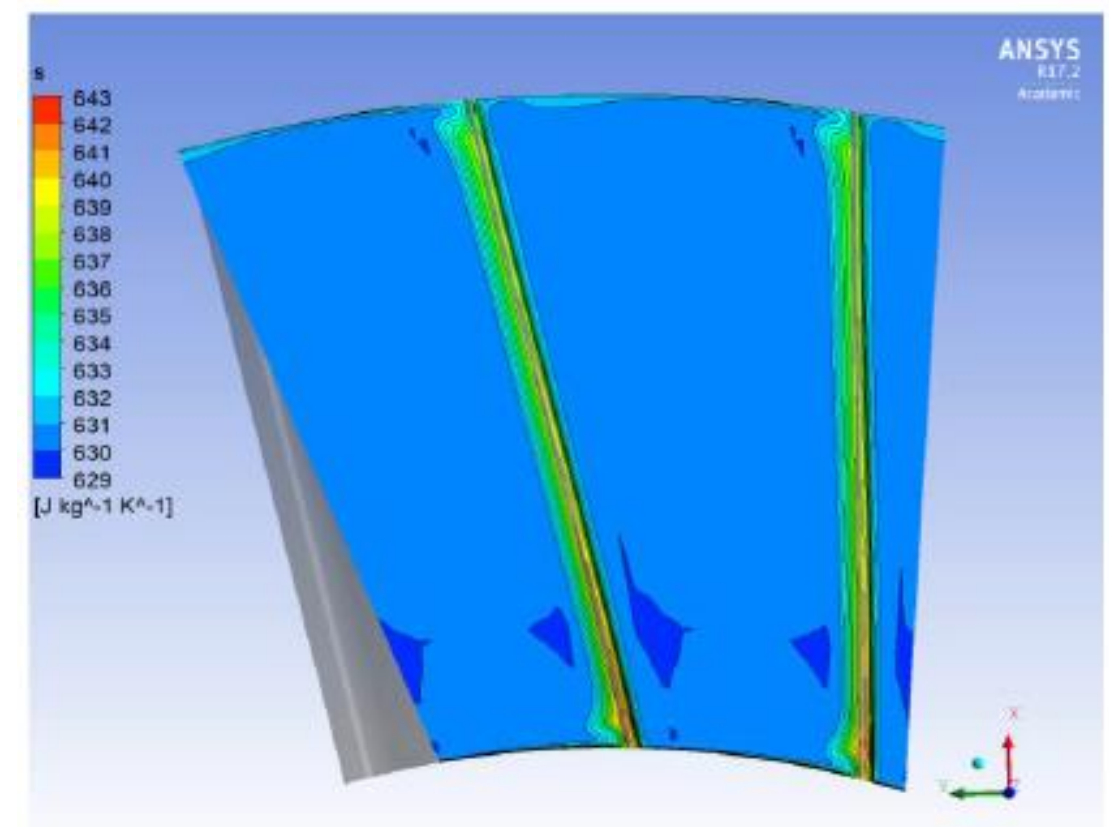

Figure 7: Change in Entropy at 8000 rpm

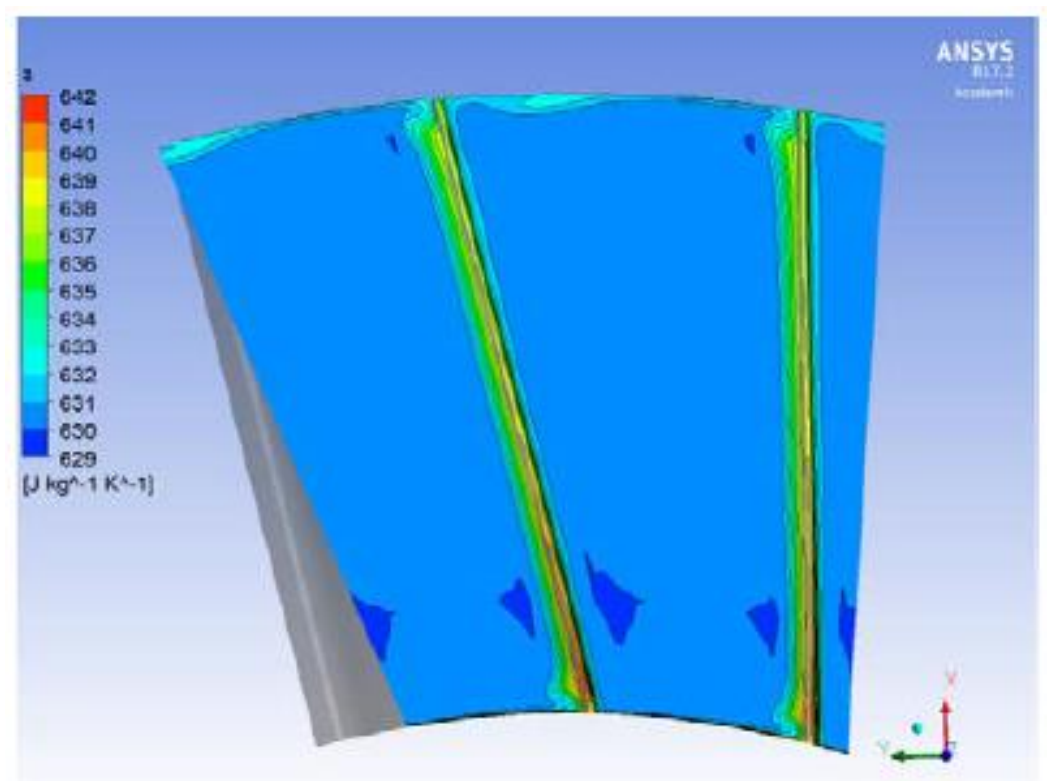

Figure 8: Change in Entropy at 9000 rpm 
International Journal of Engineering Technology and Scientific Innovation

ISSN: 2456-1851

Volume: 05, Issue: 01 "January-February 2020"

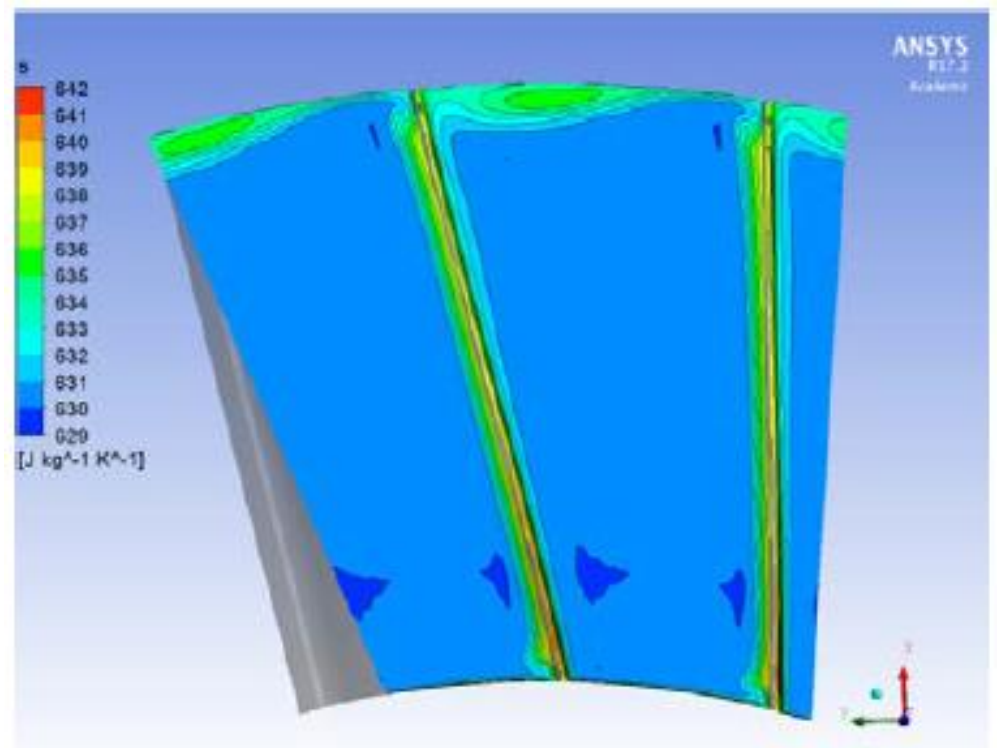

Figure 9: Change in Entropy at 13000rpm

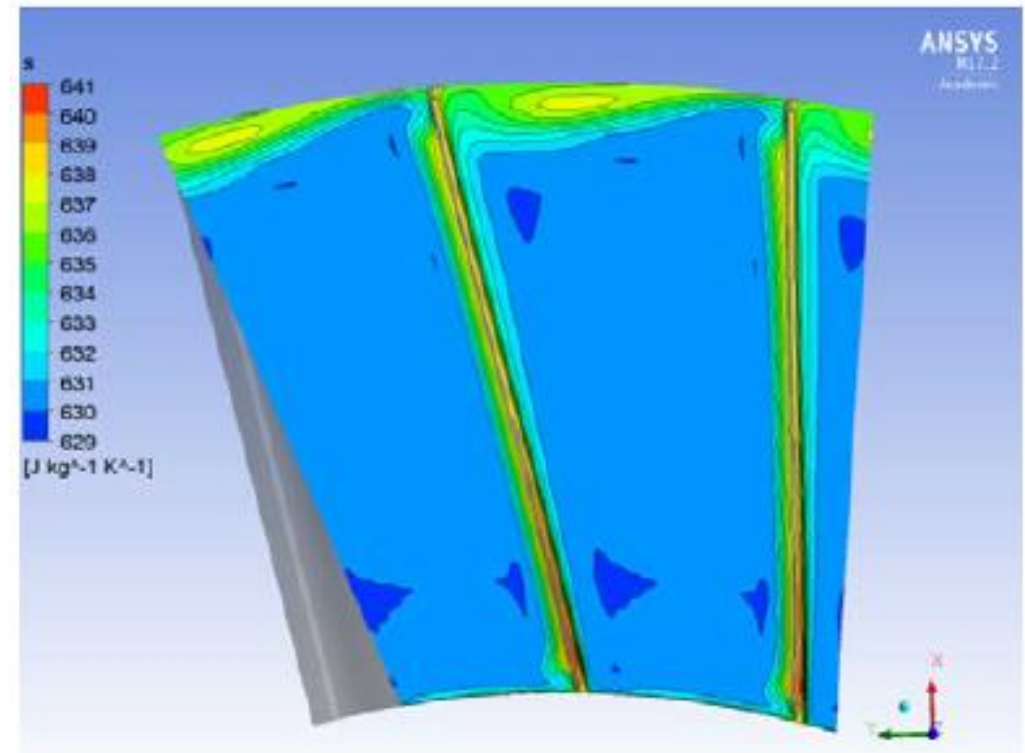

Figure 10: Change in Entropy at 15000rpm

\section{CONCLUSION}

There is a need to properly utilize the available sources of energy to meet the ever increasing 
International Journal of Engineering Technology and Scientific Innovation

ISSN: 2456-1851

Volume: 05, Issue: 01 "January-February 2020"

energy demand. Tip leakage loss reduction is one way of increasing the efficiency of gas turbine. Simulation has been done to establish the optimum rotation speed for maximum efficiency. At 9000 RPM the efficiency was maximum at $70.46 \%$, further increase lead to efficiency drop. Maximum power of $5.81 \mathrm{KW}$ was achieved at $12000 \mathrm{RPM}$.

\section{ACKNOWLEDGEMENTS}

The Government of Kenya through National Research Fund supported this work with the grant and Jomo Kenyatta University of Agriculture and Technology.

\section{REFERENCES}

1. U.S Energy Information Administration, International Energy Outlook 2016 with Projections to 2040, vol. 0484, no. May. 2016.

2. R. Bhargava, M. Bianchi, A. De Pascale, G. Negri di Montenegro, and A. Peretto, "Gas Turbine Based Power Cycles - A State-of-the-Art Review,” Power Eng. Conf., p. 11, 2007.

3. Institute of Economic Affairs (IEA), "Situational Analysis of Energy Industry, Policy and Strategy for Kenya," p. 77, 2015.

4. Energy Regulatory Commission, "Power Sector Medium Term Plan 2015-2020," vol. 21, no. 21, 2014.

5. Mobil Exxon, "The Outlook for Energy: A View to 2040," 2016.

6. B. Matveev, "Plasma or Retirement. Alternatives to the Coal-Fired Power Plants," IEEE Trans. Plasma Sci., vol. 39, no. 12 PART 1, pp. 3259-3262, 2011.

7. S. Gupta, A. Chaube, and P. Verma, "Review on Heat Transfer Augmentation Techniques: Application in Gas Turbine Blade Internal Cooling," J. Eng. Sci. Technol. Rev., vol. 5, no. 1, pp. 57-62, 2012.

8. B. Sunden and G. Xie, "Gas Turbine Blade Tip Heat Transfer and Cooling: A Literature Survey," Heat Transf. Eng., vol. 31, no. 7, pp. 527-554, 2010.

9. M. Yuri, K. Tsukagoshi, S. Hada, J. Masada, and E. Ito, "Development of $1600{ }^{\circ} \mathrm{C}-$ Class High-efficiency Gas Turbine for Power Generation Applying J-Type Technology," Mitsubishi Heavy Ind. Tech. Rev., vol. 50, no. 3, pp. 1-10, 2013.

10. M. R. Shirzadi and H. Saeidi, "The Effects of Tip Clearance on Performance of a Heavy 
International Journal of Engineering Technology and Scientific Innovation

ISSN: 2456-1851

Volume: 05, Issue: 01 "January-February 2020"

Duty Multi Stages Axial Turbine,” Proc. ASME Turbo Expo, no. June 11-15, pp. 1-11, 2012.

11. L. Qi and Y. Zhou, "Turbine Blade Tip Leakage Flow Control by Unsteady Periodic Wakes of Upstream Blade Row," Procedia Eng., vol. 80, pp. 202-205, 2014.

12. J. Gao, Q. Zheng, Y. Liu, and P. Dong, "Effects of Blade Rotation on Axial Turbine Tip Leakage Vortex Breakdown and Loss," Proc. Inst. Mech. Eng. Part G J. Aerosp. Eng., vol. 0, no. 0, pp. 1-16, 2016.

13. D. Yang and Z. Feng, "Tip Leakage Flow and Heat Transfer Predictions for Turbine Blades," Power Land, Sea Air, no. May 14-17, pp. 1-8, 2007.

14. O. Zikanov, Essential Computational Fluid Dynamics. 2010.

15. P. Bari, V. R. David, M. Torresi, B. Fortunato, and S. M. Camporeale, "Design of an Axial Impulse Turbine for Enthalpy Drop Recovery," Turbine Tech. Conf. Expo., pp. 1-12, 2014. 